\title{
Control of Emerging Contaminants in Drinking Water by Using Suitable Methods
}

\author{
S. V. Khedkar ${ }^{1}$, Dr. N. W. Ingole ${ }^{2}$. \\ ${ }^{1}$ Department Of Chemical Engineering College Of Engineering and Technology, NH-6, Murtizapur Road, \\ Babhulgaon (Jh) Akola 444104, Maharashtra State \\ ${ }^{2}$ Professor and Dean $R \& D, P R M I T \& R$ Bandera, Amravati.
}

\begin{abstract}
The environment is continuously under threat with the new products and processes being developed. A careful scrutiny of all the new products and processes is extremely essential. A class of new contaminants called as the emerging contaminants has been identified by the researchers. The emerging contaminants have different origins but are equally harmful with their effects on human and environment. The emerging contaminants require newer methods to be devised to take complete care of them. The conventional water treatment methods are insufficient to take care of the emerging contaminants. The emerging contaminants include a range of products like sunscreens, Pharmaceuticals, Flame Retardants, Disinfection Byproducts etc. The present study focuses on treatment of pharmaceutical emerging contaminant using sonication method.
\end{abstract}

Key Words: Contaminant, Disinfection, Environment, Sonication.

\section{Introduction}

There are literally hundreds of sources of emerging contaminants stemming from consumer products that end up in our wastewater, air and land. Many of these sources include everyday products such as shampoos, sunscreens, plastics, pesticides, flame retardants and pharmaceuticals. Though state and federal governments have made great strides in controlling point-source pollution from industrial sources, the diffuse pollutant stream of emerging contaminants could complicate control efforts regarding this class of chemicals. The relative contribution of each of these sources is debatable. For example, when looking at the presence of byproducts from pharmaceutical and personal care products in urban settings, wastewater treatment facilities can emit from 1,000-2,000 nano grams/liter ( $\mathrm{ng} / \mathrm{L})$ of a single compound - and are often blamed for the majority of the pharmaceutical load. Land application of bio solids from wastewater treatment onto agricultural fields may also be a significant source of emerging contaminants, as manure can contain any of the antibiotics and hormones that are used on the farm (Kjaer et al. 2007). In addition, sewage treatment facilities often offer sludge from their bioreactors to farms as fertilizers. Organic wastewater contaminants, particularly the water insoluble components, often bio accumulate to a greater degree in sludge and can have a significantly larger concentration per volume of these compounds than the treated water from the sewage plant (Kinney et al. 2006). The application of these solids on the land can therefore be a significant source of emerging contaminants and can reintroduce these compounds into the environment. Other emerging contaminants, such as flame retardants, plasticizers and coatings, are also present in wastewater effluent and sludge and are clearly tied to the quantities of the products used by the general population (e.g. Rickland et al. 2009). Brominated flame retardants, for example, are found in sludge from U.S. treatment plants at a level 10 times higher than those in Europe (Hale et al. 2003). This can partly be explained by the fact that North America consumes $98 \%$ of these chemicals, and that some of these compounds are banned in Europe in light of their persistence and toxicity. These compounds have also been found in remote locations, such as the Arctic, indicating their movement through air transport or ocean currents (de Wit et al. 2010).

\section{Pharmaceuticals:}

Pharmaceuticals are commonly found in the watersheds surrounding the Great Lakes. Where the compounds are present, they measure anywhere from 0.001 micrograms per liter $(\mathrm{ug} / \mathrm{L})$ to $0.26 \mathrm{ug} / \mathrm{L}$ closer to wastewater facilities. Metcalfe et al. (2003) is the only study to examine the open waters of the Great Lakes, sampling western Lake Erie and a few sites on Lake Ontario taken from multiple areas in Ontario, Canada including points near sewage treatment plants in Windsor and Petersborough and from the embayment of Hamilton Harbor. In this study, the highest concentrations measured were in Lake Ontario: $0.02 \mathrm{ug} / \mathrm{L}$ to 0.06 $\mathrm{ug} / \mathrm{L}$ for the medications clofibric acid (a herbicide), ketoprofen (an anti-inflamatory drug), fenoprofen (an antiinflamatory drug), and carbamazepine (a mood stabilizing drug). In sediments, pharmaceuticals ranged from 3.3 nanograms per gram (ng/g) to $75 \mathrm{ng} / \mathrm{g}$ in samples taken downstream from storm sewer outfalls. No information was provided for sediments in open lake waters. 


\section{Presence In Drinking Water}

Emerging contaminants are present in our treated drinking water, whether it comes from the treatment plant or the ground - though most are found at low levels. Current water treatment methods are not designed to remove all contaminants, and the effectiveness of removal varies depends on the compound in question and the treatment method used at each wastewater treatment plant. Benottie et al. (2009) measured for the presence of 51 chemicals in finished drinking water from 19 facilities across the United States. These chemicals included pharmaceuticals, musks, pesticides, bisphenyl A and flame retardants. The presence of emerging contaminants in finished drinking water overall was low, with a majority measuring less than $10 \mathrm{ng} / \mathrm{L}$. Chemicals found at higher concentrations included: the herbicide atrazine (median concentration $49 \mathrm{ng} / \mathrm{L}$ ); bisphenol A, found in plastics ( $25 \mathrm{ng} / \mathrm{L})$; galaxolide, a musk (31 ng/L); nonylphenol, a breakdown product from detergents $(93 \mathrm{ng} / \mathrm{L})$; BHT, a food additive $(26 \mathrm{ng} / \mathrm{L})$; metolachlor, an herbicide, $(16 \mathrm{ng} / \mathrm{L})$; DEET, an insect repellent $(63 \mathrm{ng} / \mathrm{L})$; tris(2-carboxyethyl) phosphine (TCEP), a reducing agent, (120 ng/L); and tris(1,3-dichloro-2-propyl) phosphate (TCPP), a flame retardant $(210 \mathrm{ng} / \mathrm{L})$. Some of these compounds had maximum concentrations that were much higher, including atrazine, for which the highest concentration detected was $900 \mathrm{ng} / \mathrm{L}$. Yet some samples had no detection. The authors reviewed the literature for removal efficiencies estimated by this and other studies, and found it varied from $20-90 \%$ removal depending on the compound in question. Ozone has been found to be a good oxidizer for most compounds, though even this treatment provides only partial removal of some pesticides (Broseus 2009). Emerging contaminants are also found in groundwater sources. A national survey conducted by the USGS that collected water from 47 groundwater sites across 18 states found a variety of emerging contaminants were present across sites. Most common were DEET, bisphenol A (30\%), Sulfamethoxazole (antibiotic) and Carbamazepine (antiepileptic) (Barnes et al. 2008, Focazio et al. 2008). Similar results have been found across Europe (Loos et al. 2010). This indicates that groundwater may be equivalent as a water source for emerging contaminants for those who do not directly consume Great Lakes water but are still within the basin. Groundwater also feeds into the Great Lakes and may be a source of contamination.

\section{Other Potential Human Exposures}

The most significant exposure route for some compounds in humans may not be through drinking water or surface water, but through inhalation or skin exposures, our everyday use of consumer products, and food contamination - either via the food web or from food containers leaching contaminants. For example, Johnson-Restrep and Kannan (2009) found that ingestion and skin absorption of house dust are the major pathways of exposure to the flame-retardant PBDE, comprising up to $77 \%$ of the intake of this compound. Lorber (2008) estimates house dust alone accounts for $82 \%$ of PBDE intake. Direct use of these products can also contribute to exposures. For example, levels of PBDE's in human tissues are 1-2 orders of magnitude higher in the U.S. than in Europe and Japan where PBDE's are now in limited use (Costa et al. 2008). Food contamination can be a major route of exposure that overwhelms exposure from drinking water sources. For example, exposure to phthalates — added to plastics to increase flexibility — is

\section{Emerging Contaminant The Great Lakes}

Predominantly via food and is highest in children (Lyche et al. 2009). The highest potential exposure to bisphenol A (BPA) is through contamination of food by containers that transport or hold food (European Union 2003). These containers often have linings made of epoxy resins or plastics containing BPA. Nano materials may show up in large concentrations in the environment, but for now the major exposure is most likely food products, personal care products and certain cosmetics (Dekkers et al. 2010). As many of the chemicals documented above have accumulated in freshwater organisms, including those inhabiting the Great Lakes, there is also a potential for human exposure through ingestion of Great Lakes fish - exposures that have been documented in studies of polychlorinated biphenyls (PCBs) and other known persistent contaminants. As contaminant concentrations in fish are often greater than those of the surrounding waters, each fish consumed contains a greater amount of emerging contaminants than an equivalent amount of water.

\section{New Wastewater Technologies}

Various wastewater treatment processes that amend current techniques have been proposed to improve the removal of emerging contaminants. These include adding steps in the treatment process such as activated carbon, UV in combination with an oxidizing agent and others. Activated carbon appears to show a significant removal capacity, and UV and photocatalytic reactions (Méndez-Arriaga et al. 2010, 2008) may also assist in degrading these contaminants. Nanomaterials, paradoxically themselves a potential emerging contaminant of concern, have also been proposed as an addition to the treatment system. Membranes, oxidants and adsorbents made from nanomaterials have been proposed as a lower-cost treatment option (Bottero et al. 2006). These materials also bear a potential cost, as their production can produce significant waste and the impact of their release into the environment is, for the most part, unknown. It is important to note that these solutions may solve 
the problem of the release of only certain contaminants into the environment. There are many others that are airborne or enter our environment through means other than wastewater treatment facilities, such as through agriculture, septic systems and factory pollution.

\section{Sonication As New Wastewater Technology}

Ultrasound technology is used as a modern and very environment friendly process in an increasing number of applications and processes of the chemical industry. Particularly noteworthy are the application options of this technology in pharmacy, chemistry, biotechnology, and environmental engineering. The applications make use of the various effects of ultrasound for the processing of gaseous, liquid, and solid media. Ultrasound process technology is a unique method for the activation and acceleration of processes in chemistry, petro chemistry, and biotechnology. In chemical synthesis, ultrasound supports organo metal intermediary products and promotes most types of catalytic processes. Moreover, ultrasound has a generally accelerating and favorable impact on heterogeneous reactions. Another special application of ultrasound is its use in environmental engineering. Some water clarification plants have started to use ultrasound to disintegrate sludge. Another application from the realm of environmental engineering is the use of ultrasound in potable water treatment.

\section{Acoustic Cavitation}

Acoustic cavitation is effected using the high frequency sound waves usually ultrasound, with frequency range of $16 \mathrm{kHz}-100 \mathrm{kHz}$. Alternate compression and rarefaction cycles of sound waves result in various phases of cavitation such as generation of bubble/cavity, growth phase and finally collapse phase releasing large amount of energy locally (Gogate Parag 2002). Ultrasound occurs at a frequency above $16 \mathrm{kHz}$ (Uma Mukherji 2003), higher than the audible frequency of the human ear, and is typically associated with the frequency range of $20 \mathrm{kHz}$ to $500 \mathrm{MHz}$. The frequency level is inversely proportional to the power output. Lowintensity, high-frequency ultrasound (in the megahertz range) does not alter the state of the medium through which it travels and is commonly used for non destructive valuation and medical diagnosis. However, highintensity, low-frequency ultrasound does alter the state of the medium and is the type of ultrasound typically used for sonochem-ical applications. The applications of ultrasound are briefly explained in the Kirk Othmer Encyclopedia of Chemical Technology.

There are several references available which provide a general overview of the field of sonochemistry and the types of chemical reactions which have been studied. Some authors Mason T.J., 1990; Mason T.J. and Lorimer J.P., 2002, Jose Gonzalez-Garcia et al., 2010). Some authors have compared the various effects of ultrasound to other types of chemistry, such as mechano chemistry. However, as will be evident from this review, it will take the combined effort of scientists and engineers to thoroughly understand sonochemical reactions and develop rational design procedures for sonochemical reactors.

\section{METHODS TO INTRODUCE ULTRASOUND IN REACTION VESSEL}

There are basically two methods for the introduction of ultrasound in the reaction system. The reaction vessel itself maybe immersed in liquid (generally water) which itself is under irradiation (e.g. cleaning bath or the cup horn device) or an ultrasonic probe can be placed directly into the reaction system. Whichever system is adopted it is essential to control the temperature and irradiation power to produce repeatable results. The most commonly used reaction systems are described below.

\section{Ultrasonic Bath}

The construction of ultrasonic bath is simple. It consists of a stainless steel tank with transducers clamped to its base. The low intensity ultrasonic bath systems have power densities of $1-2 \mathrm{~W} / \mathrm{cm}^{2}$. For small baths a single transducer may be sufficient but for larger systems a number of transducers may be employed to introduce higher power densities into the liquid. The frequency and power of an ultrasonic bath depends upon the type and number of transducers used in its construction.

\section{Direct Immersion Horn}

A number of disadvantages of the use of simple cleaning ultrasonic bath can be avoided using ultrasonic probe. The ultrasonic probe horn is adaptation of the biological cell disrupters. The ultrasonic probe can be directly inserted into the reaction mixture. The probe more correctly termed a sonic horn or velocity transformer is driven by a transducer and ultrasound enters the reaction mixture through the probe tip. The intensity of sonication, the vibration amplitude of the tip, can be controlled by altering the power input to the transducer and all sonicators have power control. The modern systems are designed to operate with a range of detachable probes having different tip diameters. Probe systems are the most efficient in transferring ultrasonic energy in laboratory reaction systems. 


\section{Aspirin As Emerging Contaminant}

A study of the sono degradation of pharmaceutical drug aspirin (Disprin tablet) is presented in this research work. Aspirin occurs in pharmaceutical waste water as waste from pharmaceutical industry. It also occurs in natural water like lake \& river water as contaminant. Aspirin is widely used as an analgesic in many countries of the world. Aspirin is considered a life saving drug. The occurrence of aspirin in lake and river waters is also high in comparison with other drugs. Aspirin (acetylsalicylic acid, ASA) is a drug that hydrolyzes according to the chemical equation:

$\mathrm{HOOC}-\mathrm{C}_{6} \mathrm{H}_{4}-\mathrm{COOCH}_{3}+\mathrm{H}_{2} \mathrm{O}=\mathrm{HOOC}-\mathrm{C}_{6} \mathrm{H}_{4}-\mathrm{OH}+\mathrm{CH}_{3} \mathrm{COOH}$ (1)

$$
\text { aspirin salicylic acid acetic acid }
$$

$($ molecular wt. $=180) \quad($ molecular wt. $=138) \quad($ molecular wt $=60)$

This hydrolysis is evident by the smell of acetic acid detected when a bottle of aspirin is opened. The rate of hydrolysis is dependent on the temperature, $\mathrm{pH}$ and amount of moisture present. This research work is carried out with the objective to study the process of sono degradation of aspirin and evaluate the efficiency of the process with respect to degradation for different concentrations of aspirin.

\section{Aspirin Treatment By Direct Immersion Horn}

Dispersible disprin tablets were used as the source of Aspirin. Each dispersible tablet contained $350 \mathrm{mg}$ of Aspirin. A number of tablets 1-5 were used to prepare the solutions of different concentrations. Deionised water was used to prepare the sample solution. Deionised water used was of A.R. grade.

\section{A Methods}

The synthetic sample obtained was sonicated in sonication system consisting of a probe of $18 \mathrm{~mm}$ diameter and the US frequency of $20 \mathrm{kHz}$. The samples were sonicated varying the parameters both on the liquid side as well as machine side parameters. The machine side parameters varied were Amplitude and the Sonication time. The liquid side parameters varied included the $\mathrm{pH}$ and the concentration of the sample. The studies were conducted on samples in batch mode. The temperatures varied during the intense process of sonication.

\section{Observations}

\begin{tabular}{|l|l|l|l|l|}
\hline s.no & Optimization time required & Concentration in $\mathrm{mg} / \mathrm{lit}$ & Amplitude of Sonication & $\%$ Aspirin Degraded \\
\hline 1 & 15 & 700 & 100 & 91.30 \\
\hline 2 & 30 & 1400 & 100 & 91.30 \\
\hline 3 & 45 & 2100 & 100 & 91.30 \\
\hline 4 & 60 & 2800 & 100 & 91.30 \\
\hline 5 & 75 & 3500 & 100 & 91.30 \\
\hline
\end{tabular}

Table II

\begin{tabular}{|l|l|l|l|l|}
\hline S.no & Time of sonication & Concentration in $\mathrm{mg} / \mathrm{lit}$ & Amplitude of Sonication & \% Aspirin Degraded \\
\hline 1. & 5 & 700 & 100 & 86.57 \\
\hline 2. & 10 & 700 & 100 & 91.30 \\
\hline 3. & 15 & 700 & 100 & 91.30 \\
\hline 4. & 5 & 1400 & 100 & 30.35 \\
\hline 5. & 10 & 1400 & 100 & 34.79 \\
\hline 6. & 15 & 1400 & 100 & 41.31 \\
\hline 7. & 20 & 1400 & 100 & 56.53 \\
\hline 8. & 25 & 1400 & 100 & 80.44 \\
\hline 9. & 30 & 1400 & 100 & 91.30 \\
\hline
\end{tabular}

II. Results \& Discussion

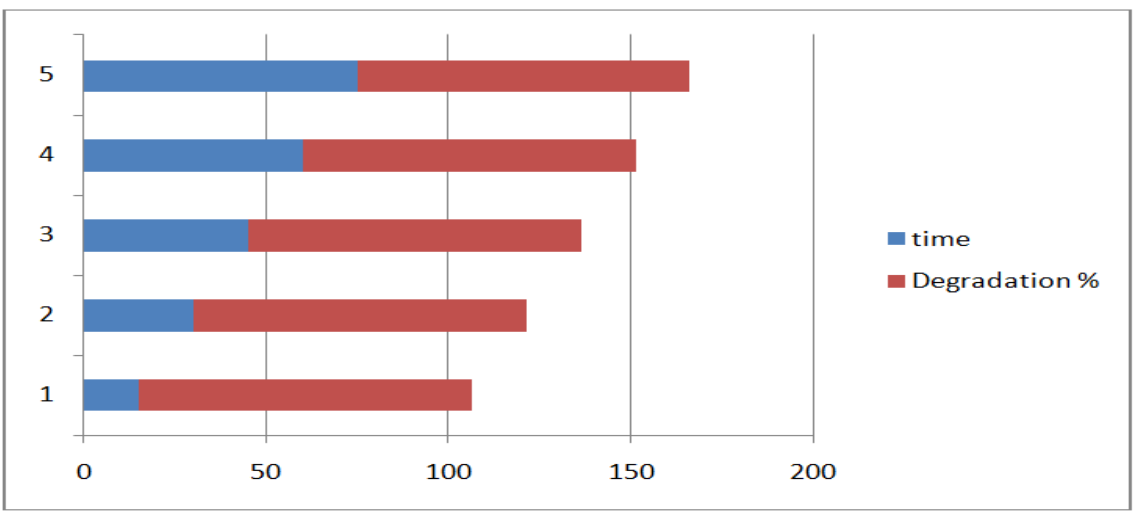

Fig 1 time of degradation with \% degradation for various concentrations of aspirin 
From the fig 1 above it is clear that for different concentrations $(700,1400,2100,2800,3500 \mathrm{mg} / \mathrm{lit}) \mathrm{of}$ the treated solutions of Aspirin the time has increased with concentration but at the same the degree of treatment or $\%$ degradation has remained constant.

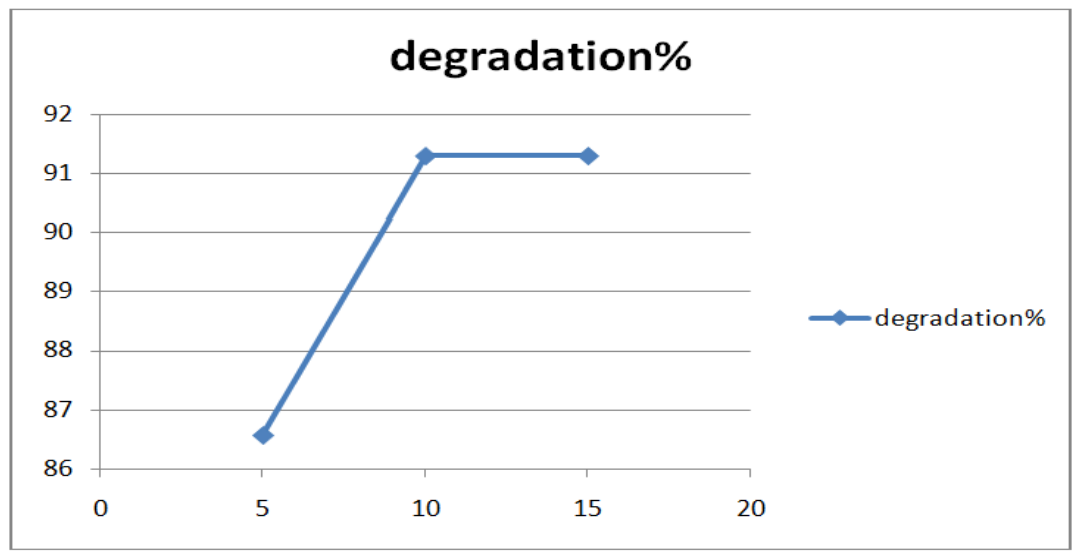

Fig 2 time versus \% aspirin degraded for concentration of $700 \mathrm{mg} / \mathrm{lit}$

The fig 2 above depicts the degradation of Aspirin solution of $700 \mathrm{mg} / \mathrm{lit}$ from the fig it is clear that the initial degradation is faster and greater after which it is almost constant. The final \% degradation is 91.30 .

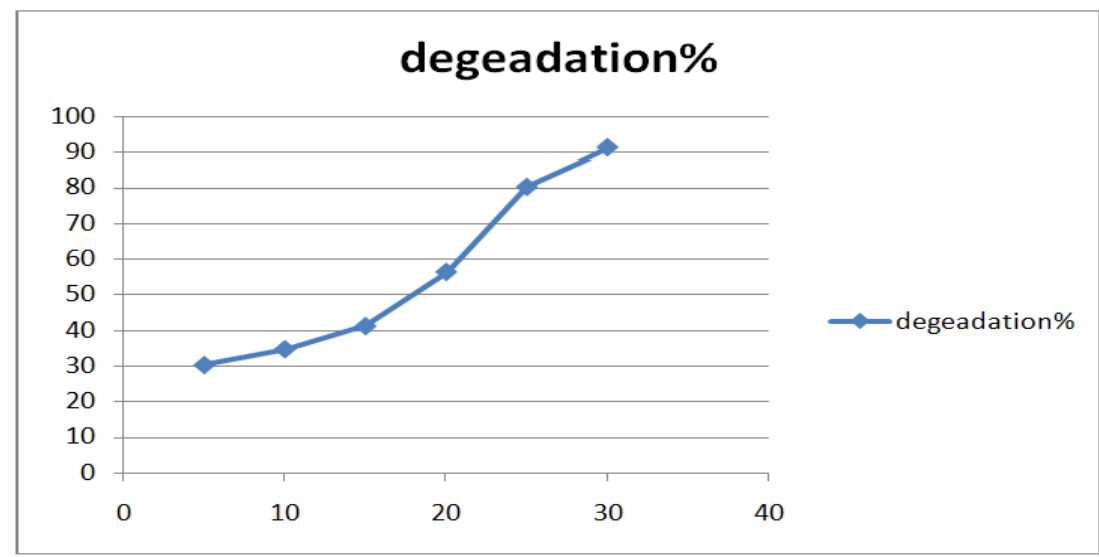

Fig 3 times versus \% aspirin degraded for concentration of

The fig 3 above depicts the degradation of Aspirin solution of $1400 \mathrm{mg} / \mathrm{lit}$ from the fig it is clear that the degradation is follows a steeply rising degradation curve after which it is almost constant after attaining the final degradation $\%$ of $91.30 \%$.

\section{Conclusions}

From the results and discussion its clear that Aspirin in drinking water can be treated with the sonication method. Aspirin in the normal course takes very long to degrade in the environment. The sample results for two concentrations have been presented above. The final degradation of $91.30 \%$ has been obtained in both the cases. It can be improved further with further adjustment of machine parameters. Conventional methods of treatment cannot treat Aspirin hence its essential to use newer methods.

\section{References}

[1] Barnes, K.K., Kolpin, D.W., Furlong, E.T., Zaugg, S.D., Meyer, M.T., Barber, L.B., 2008.Anational reconnaissance ofpharmaceuticals and other organic wastewater contaminants in the United States e I) Ground water. Sci. Total Environ. 402, 192200 .

[2] Benotti MJ, Trenholm RA, Vanderford BJ, Holady JC, Stanford BD, Snyder SA.Pharmaceuticals and endocrine disrupting compounds in U.S. drinking water.Environ Sci Technol. 2009 Feb 1;43(3):597-603.

[3] Broséus R, Vincent S, Aboulfadl K, Daneshvar A, Sauvé S, Barbeau B, Prévost M. Ozone oxidation of pharmaceuticals, endocrine disruptors and pesticides during drinking water treatment. Water Res. 2009 Oct;43(18):4707-17.

[4] Bottero JY, Rose J, Wiesner MR. Nanotechnologies: tools for sustainability in a new wave of water treatment processes. Integr Environ Assess Manag. 2006 Oct;2(4):391-5.

[5] Costa LG, Giordano G. Developmental neurotoxicity of polybrominated diphenyl ether (PBDE) flame retardants. NeuroToxicology 2007; 28: 1047-67. 
[6] de Wit CA, Herzke D, Vorkamp K. Brominated flame retardants in the Arctic environment--trends and new candidates. Sci Total Environ. 2010 Jul 1;408(15):2885-918.

[7] Dekkers S, Krystek P, Peters RJ, Lankveld DX, Bokkers BG, van Hoeven-Arentzen PH, Bouwmeester H, Oomen AG. Presence and risks of nanosilica in food products. RIVM (National Institute for Public Health and the Environment), Bilthoven. Nanotoxicology. 2010 Sep 24.

[8] Focazio, M.J., Kolpin, D.W., Barnes, K.K., Furlong, E.T., Meyer, M.T., Zaugg, S.T., Barber, L.B., Thurman, M.E., 2008. A national reconnaissance for pharmaceuticals and other organic wastewater contaminants in the United States II) Untreated drinking water sources. Sci. Total Environ. 402, 201-216.

[9] Parag R. Gogate 2002, "Cavitation: an auxiliary technique in wastewater treatment schemes". Advances in Environmental Research (6), pp 335-358.

[10] Hale RC, Alaee M, Manchester-Neesvig JB, Stapleton HM, Ikonomou MG.Polybrominated diphenyl ether flame retardants in the North American environment. Environ Int. 2003 Sep;29(6):771-9.

[11] José González-García et al., 2010, "Sonochemical Treatment of Water Polluted by Chlorinated Organo Compounds - A Review", Water 2010, 2, pp 28-74; doi: 10.3390/w2010028.

[12] Johnson-Restrepo B, Kannan K. An assessment of sources and pathways of human exposure to polybrominated diphenyl ethers in the United States. Chemosphere. 2009 Jul;76(4):542-8. Epub 2009 Apr 5.

[13] Kinney CA, Furlong ET, Zaugg SD, Burkhard MR, Werner SL, Cahill JD, Jorgensen GR. Survey of organic wastewater contaminants in biosolids destined for land application. Environ Sci Technol. 2006 Dec 1;40(23):7207-15.

[14] Kjaer J, Olsen P, Bach K, Barlebo HC, Ingerslev F, Hansen M, Sørensen BH.Leaching of estrogenic hormones from manure-treated structured soils. Environ Sci Technol. 2007 Jun 1;41(11):3911-7.

[15] Lyche JL, Gutleb AC, Bergman A, Eriksen GS, Murk AJ, Ropstad E, Saunders M, Skaare JU. Reproductive and developmental toxicity of phthalates. J Toxicol Environ Health B Crit Rev. 2009 Apr;12(4):225-49.

[16] Loos R, Locoro G, Comero S, Contini S, Schwesig D, Werres F, Balsaa P, Gans O, Weiss S, Blaha L, Bolchi M, Gawlik BM. PanEuropean survey on the occurrence of selected polar organic persistent pollutants in ground water. Water Res. 2010 Jul;44(14):4115-26.

[17] Lorber M. Exposure of Americans to polybrominated diphenyl ethers. J Expo Sci Environ Epidemiol. 2008 Jan;18(1):2-19. Epub 2007 Apr 11. Review.

[18] Méndez-Arriaga F, Esplugas S, Giménez J. Degradation of the emerging contaminant ibuprofen in water by photo-Fenton.Water Res. 2010 Jan;44(2):589-95.

[19] Metcalfe, C. D., Miao, X.-S., Koenig, B. G. and Struger, J. (2003), Distribution of acidic and neutral drugs in surface waters near sewage treatment plants in the lower Great Lakes, Canada. Environmental Toxicology and Chemistry, 22: 2881-2889. doi: $10.1897 / 02-627$.

[20] T. J. Mason 1990, “Chemistry with Ultrasound”, Published by Springer, Edition 1990, ISBN No. 9781851664221, pp, 1-208.

[21] T.J. Mason andJ.P.Lorimer 2002, “Applied Sonochemistry: Uses Of Power Ultrasound in Chemistry and Processing". Wiley - VCH Verlag GmbH \& Co. KGaA. ISBNs: 3-527-30205-0 (Hardback) 3-527-60054-x(Electronic).

[22] Ricklund N, Kierkegaard A, McLachlan MS, Wahlberg C. Mass balance of decabromodiphenyl ethane and decabromodiphenyl ether in a WWTP. Chemosphere. 2009 Jan;74(3):389-94.

[23] Uma Mukherji, 2003, "Engineering Physics”, Narosa Publishing House, ISBN 81-7319-240-5, pp 69-84. 